Proceedings of the International Symposium on Physics of Materials (ISPMA 14), September 10-15, 2017, Prague

\title{
Comparison of Microstructure and Texture Evolution of MX20, Conventionally Rolled and Rolled from Twin Roll Cast Strip
}

\author{
G. Kurz*, T. Petersen, R. Hoppe, J. Bohlen and D. Letzig \\ Magnesium Innovation Centre, Max-Planck-Str. 1, 21502 Geesthacht, Germany
}

\begin{abstract}
Different production processes like casting and twin roll casting of Mg-based alloys have a significant influence on the microstructure and texture of the resulting feedstock material for the subsequent rolling process. This leads to improved mechanical properties in the final sheets produced by twin roll casting. In this paper the processing of an Mg-based alloy MX20 (2 wt\% Mn and $0.5 \mathrm{wt} \% \mathrm{Ca}$ ) is demonstrated in a modified gravity casting process as well as in the twin roll casting process. The paper will show the different microstructures of the cast and twin roll cast feedstock material. Rolling trials are conducted and the mechanical properties of the sheets are presented and discussed with respect to arising microstructures and textures. The results demonstrate that the different morphology of precipitates in the cast and the twin roll cast feedstock material is used to improve the mechanical properties of the twin roll cast sheets.
\end{abstract}

DOI: 10.12693/APhysPolA.134.703

PACS/topics: 62.20.F-, 81.05.Bx, 81.40.Ef, 81.40.Gh

\section{Introduction}

It is principally accepted that the comparably low formability of Mg-alloy based sheets is caused by a limited number of slip systems that could be activated, at least in comparison to metals with a cubic crystal structure like Al. The low formability $[1,2]$ of magnesium crystals has a significant impact on the processing linked with plastic deformation. The properties of rolled magnesium sheets like ductility, strength and corrosion resistance are improved by alloying with rare earth elements [3]. Magnesium sheet materials with the addition of rare earths elements show a more randomized (weaker) texture and fine-grained microstructure [4-6]. The addition of these elements improves the mechanical properties of rolled Mg-sheets.

The commercial alloy ME21 does not contain aluminum as an alloying element. This means there is no low-melting eutectic in contrast to the aluminumcontaining Mg alloys. The alloy ME21 has the advantage of a high strength at elevated temperatures and a high creep resistance in comparison to other magnesium alloys [7]. Generally, the addition of rare earth elements is problematic from several points of view. Because of their strategic importance for many industrial applications and the tight supply situation they are classified as a critical resource group whose supply is associated with high costs and leads to economic dependences on imports of these elements. In addition, the production of these substances requires enormous efforts and causes major environmental problems that should be avoided in

*corresponding author; e-mail: Gerrit.kurz@hzg.de terms of a sustainable material selection for industrial use. Adding $\mathrm{Ca}$ to $\mathrm{Mg}-\mathrm{Zn}$-based alloys shows a similar texture evolution and texture behavior as RE containing alloys $[7,8]$.

This work will report on the effects of Mn-based alloys with calcium as a substitution for rare earth elements, with respect to the arising sheet properties. Furthermore, it will be discussed how different processing routes like rolling from the billet or twin roll casting and rolling influence the microstructure, texture and the resulting mechanical properties. Because of the very high solidification rate in the twin roll casting process this process will have an influence on the materials properties.

\section{Experimental procedure}

For the conventional sheet production process the alloy MX20 (2 wt\% Mn and $0.5 \mathrm{wt} \% \mathrm{Ca}$ ) is cast in cubic billets $(120 \mathrm{~mm} \times 70 \mathrm{~mm} \times 270 \mathrm{~mm})$ using a modified gravity casting process. After casting the billets were heat treated at $450^{\circ} \mathrm{C}$ for $16 \mathrm{~h}$ to homogenize the microstructure and to reduce the amount of precipitates. In parallel, strips of MX20 were produced by twin roll casting. This was done at the Institute of Metal Forming at the TU Bergakademie Freiberg. These strips received a homogenization heat treatment at $460^{\circ} \mathrm{C}$ for $8 \mathrm{~h}$. For the rolling trials the billets were machined down to dimensions of $20 \mathrm{~mm} \times 100 \mathrm{~mm} \times 200 \mathrm{~mm}$. The strip material had the dimensions of $330 \mathrm{~mm} \times 600 \mathrm{~mm} \times 5 \mathrm{~mm}$. Both feedstock materials were rolled down on a Danieli rolling mill with roll dimensions of $360 \mathrm{~mm} \times 500 \mathrm{~mm}$. The different feedstocks were rolled at a temperature of $450^{\circ} \mathrm{C}$ and the rolling procedure consisted of two rolling schedules of 7 respectively 15 passes with different degrees of deformation between $\varphi=0.1$ and $\varphi=0.2$, leading to a final gauge of approximately $1.5 \mathrm{~mm}$. Here $\varphi$ is given as 


$$
\phi=-\ln \left(h_{n+1} / h_{n}\right),
$$

where $n$ is the number of the passes and $h_{n}$ is the sample thickness after the pass $n$. In order to homogenize the microstructure of the sheets, a heat treatment of $1 \mathrm{~h}$ at $450{ }^{\circ} \mathrm{C}$ was carried out after rolling. After all processing steps, the microstructures of the materials were analyzed by using optical microscopy. Standard metallographic sample preparation techniques were employed and an etchant based on picric acid was used to reveal grains and grain boundaries [9]. Texture measurements were performed on the sheet mid-planes using a Panalytical X-ray diffractometer setup. The pole figures were measured up to a tilt angle of $70^{\circ}$, which allowed the recalculation of full pole figures based on a MTEX software routine [10]. Subsequent tensile tests were conducted with a constant initial strain rate of $1.0 \times 10^{-3} \mathrm{~s}^{-1}$ to see how the different processing routes influence the mechanical properties of the sheets. After a heat treatment the samples for the tensile tests were prepared in rolling and transverse direction of the sheets.

\section{Casting trials}

Figure 1 displays the MX20 microstructure of the cast billet in the as cast condition as well as after the heat treatment. The MX20 billet exhibits a coarse grained dendritic microstructure with a very inhomogeneous grain size distribution.
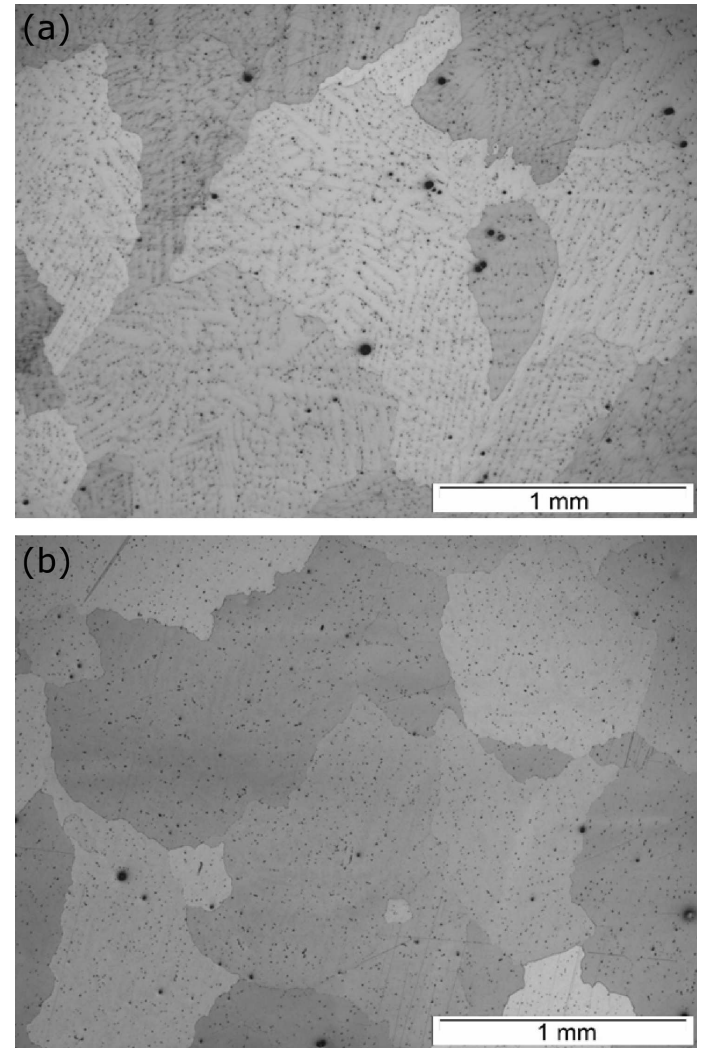

Fig. 1. MX20 in the as cast condition (a) and as cast and heat treated at $450^{\circ} \mathrm{C}$ for $16 \mathrm{~h} \mathrm{(b)}$.

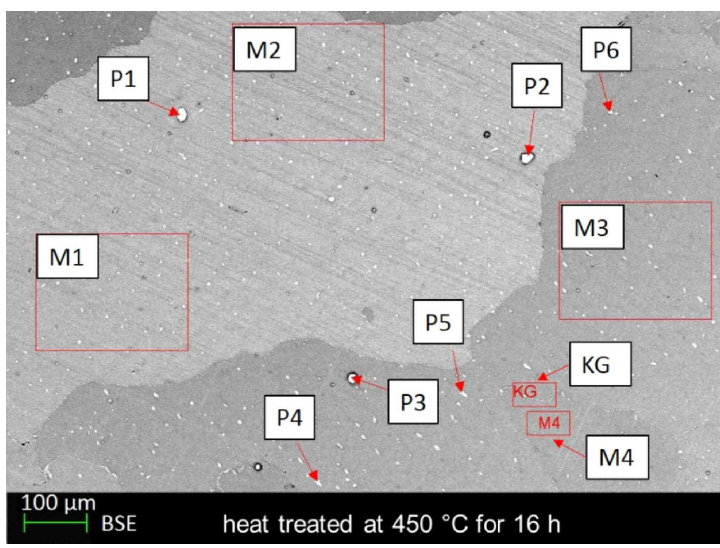

Fig. 2. EDX analysis of the cast MX20 billet.

Results of EDX analysis of the cast MX20

TABLE I billet ( $\mathrm{Mg}$ in balance; values in at.\%)

\begin{tabular}{l|c|c|c|c}
\hline \hline & $\mathrm{Mn}$ & $\mathrm{Ca}$ & $\mathrm{Si}$ & $\mathrm{O}$ \\
\hline \multicolumn{5}{c}{$(\mathrm{Mn})$-phase } \\
\hline P1-P3 & 80 & 0.05 & 0.5 & 13 \\
$\mathrm{P} 6$ & 59 & 0.1 & 1 & 19 \\
\hline \multicolumn{5}{c}{$\mathrm{Mg}_{2}$ Ca-phase } \\
\hline P4-P5 & 0.35 & 7.5 & 0.1 & 8 \\
\hline \multicolumn{5}{c}{$(\mathrm{Mg})$} \\
\hline M1-M4 & 0.7 & 0.3 & 0.1 & 1.75 \\
\hline KG & 0.8 & 0.3 & 0.07 & 1.7
\end{tabular}
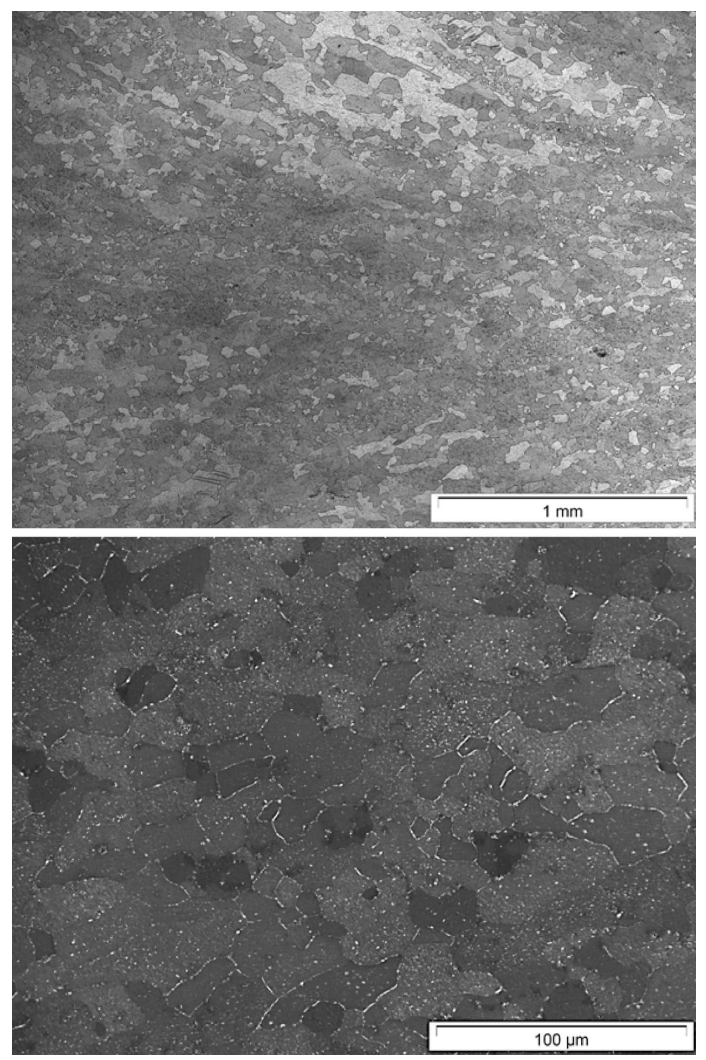

Fig. 3. MX20 twin roll cast and heat treated at $460{ }^{\circ} \mathrm{C}$ for $8 \mathrm{~h}$. 


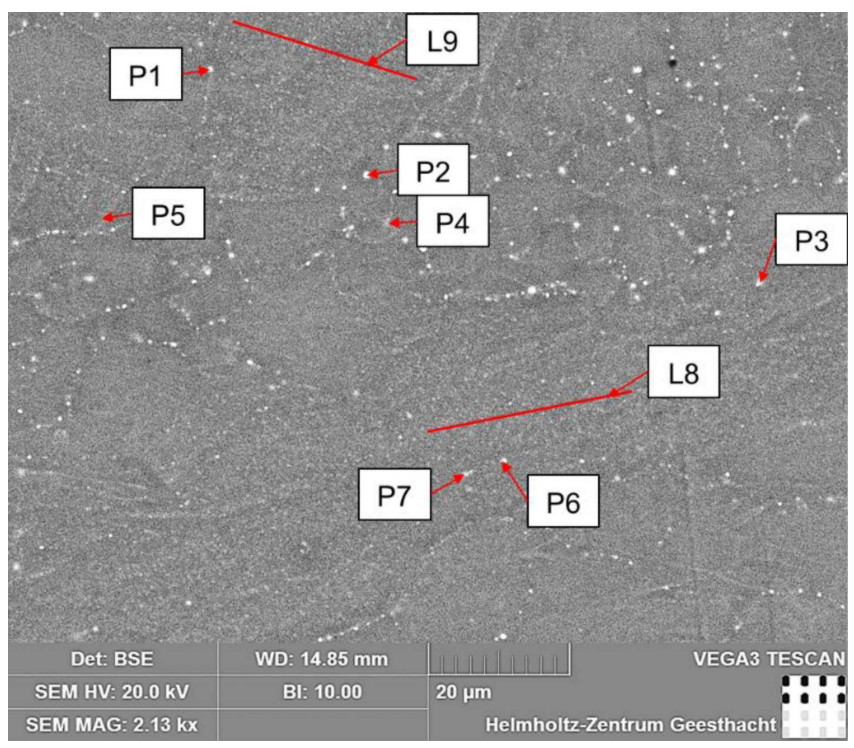

Fig. 4. EDX analysis of MX20 twin roll cast strip heat treated at $460{ }^{\circ} \mathrm{C}$ for $8 \mathrm{~h}$.

A small number of coarse Mn containing precipitates can be observed in the grains by EDS-analysis (Fig. 2, Table 1). Furthermore, finer Ca containing precipitates are detected in the grains along the dendrite arms. The heat treatment of $16 \mathrm{~h}$ at $450{ }^{\circ} \mathrm{C}$ reduces the number of precipitates at grain boundaries. The dendritic microstructure disappears also in the grains.
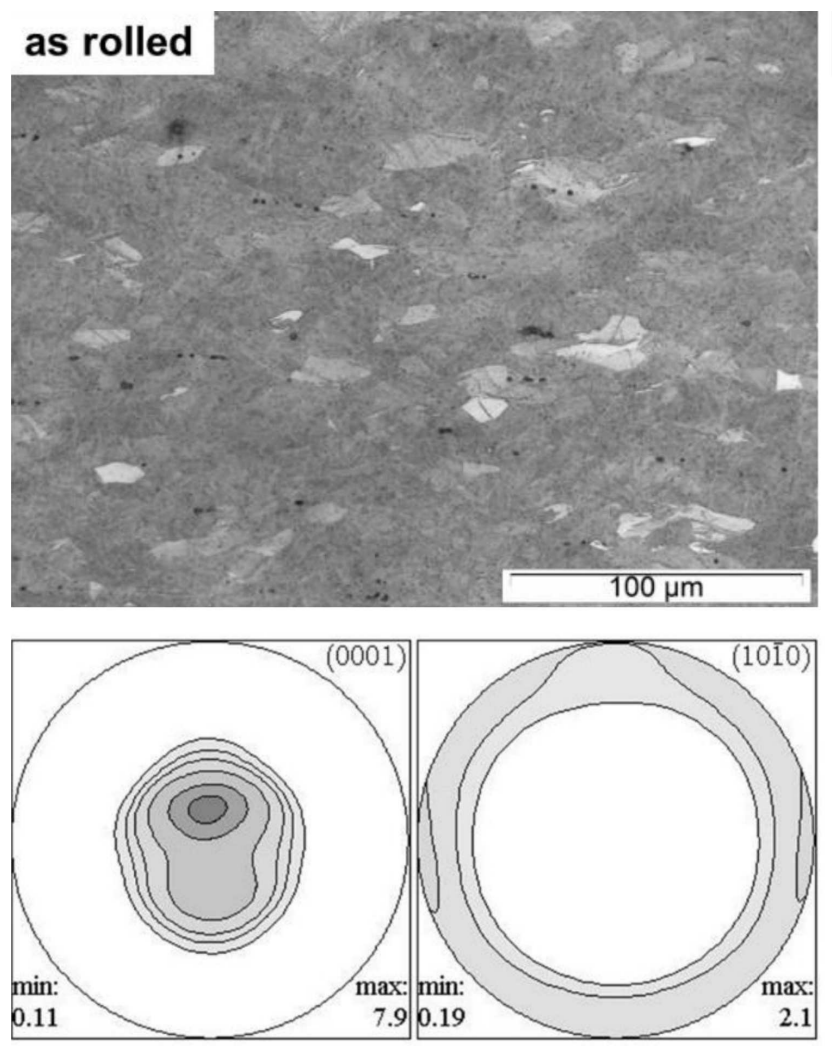

The microstructure of the twin roll cast strip is presented in Fig. 3. The material shows the typical microstructure of twin roll cast strip, some elongated, columnar grains in the top and bottom area and center equiaxed grains. But, most grains in the top and bottom area are also equiaxed, because of the deformation induced by the rolling pass. In comparison to the cast and heat treated billet the microstructure in the heat treated twin roll cast strip is much finer.

The EDX analysis of twin roll cast strip demonstrates that the precipitates in the microstructure are mainly located at the grain boundaries and the precipitates are much finer, by comparison to the cast material (Fig. 4, Table II).

TABLE II

Results of EDX analysis of MX20 twin roll cast strip heat treated at $460{ }^{\circ} \mathrm{C}$ for $8 \mathrm{~h}$ (Values in at.\%)

\begin{tabular}{c|c|c|c}
\hline \hline & $\mathrm{Mg}$ & $\mathrm{Ca}$ & $\mathrm{Mn}$ \\
\hline P1 & 90.734 & 0.188 & 1.834 \\
P2 & 81.8 & 0.518 & 7.468 \\
P3 & 91.578 & 0.35 & 0.739 \\
P4 & 90.18 & 0.717 & 0.846 \\
P5 & 90.778 & 0.801 & 0.641 \\
P6 & 89.783 & 0.114 & 0.693 \\
P7 & 91.079 & 0.29 & 0.889 \\
L8 & 93.85 & 0.22 & 1.61 \\
L9 & 93.81 & 0.23 & 1.65
\end{tabular}
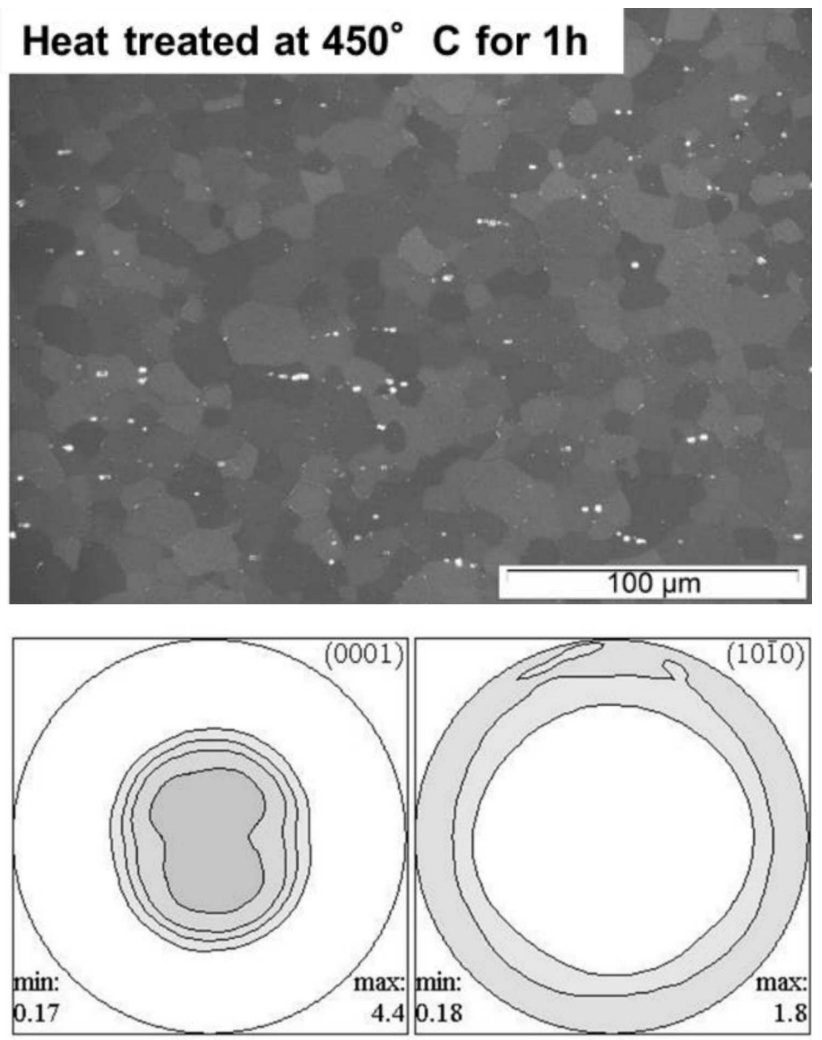

Fig. 5. Microstructure of a MX20 sheet rolled from the cast billet. 

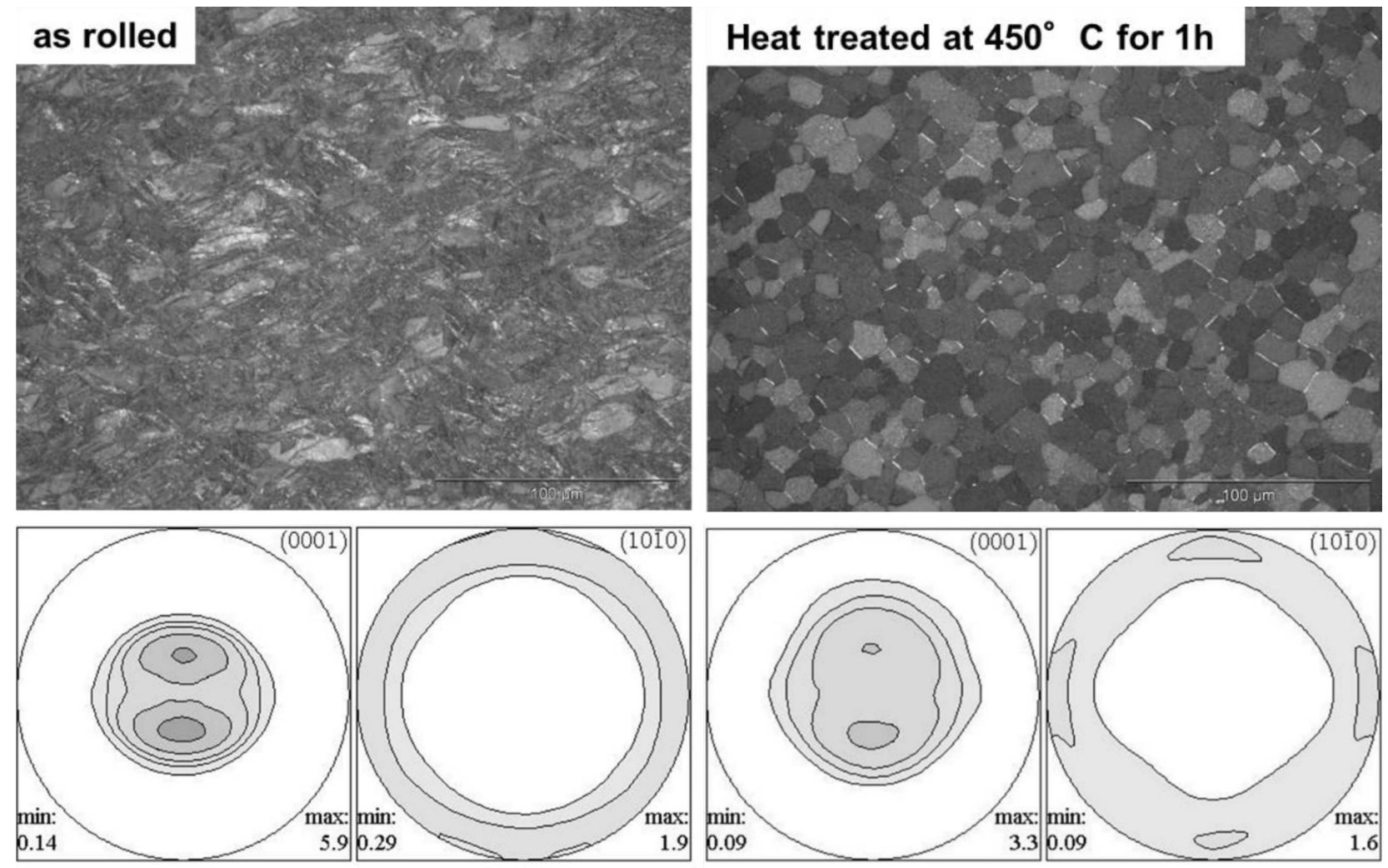

Fig. 6. Microstructure of a MX20 sheet rolled from twin roll cast strip.

\section{Rolling trials}

The microstructures of both sheets are presented in Figs. 5 and 6 in the as rolled condition and after the heat treatment. The microstructures of both sheets are not fully recrystallized after the rolling process. After the heat treatment both sheets exhibit a fully recrystallized microstructure. Furthermore, in the sheet produced out of the cast billets some $\mathrm{Mn}$ containing precipitates are aligned in small lines, so-called stringers. These stringers are associated with particles from the original cast billet structure that also underwent deformation, i.e. they did not form during rolling procedure. The sheet rolled from the TRC-strip shows also a fine and homogeneous microstructure. In comparison to the sheet rolled from the cast billet the precipitates in this sheet are all located at the grain boundaries (Fig. 6).

The basal and prismatic pole figures, after rolling and after heat treatment are also presented in Figs. 5 and 6 . The textures could best be described by an alignment of basal planes close to the sheet plane but with a split peak component in the basal pole figure with tilt towards the rolling direction. This is more developed in case of the rolled TRC-strip whereas the split peaks appears degenerated in one tilt peak in case of the rolled cast ingot. The pole figures of both sheets show distinctly lower intensities after the heat treatment. However, the split peak texture is maintained.
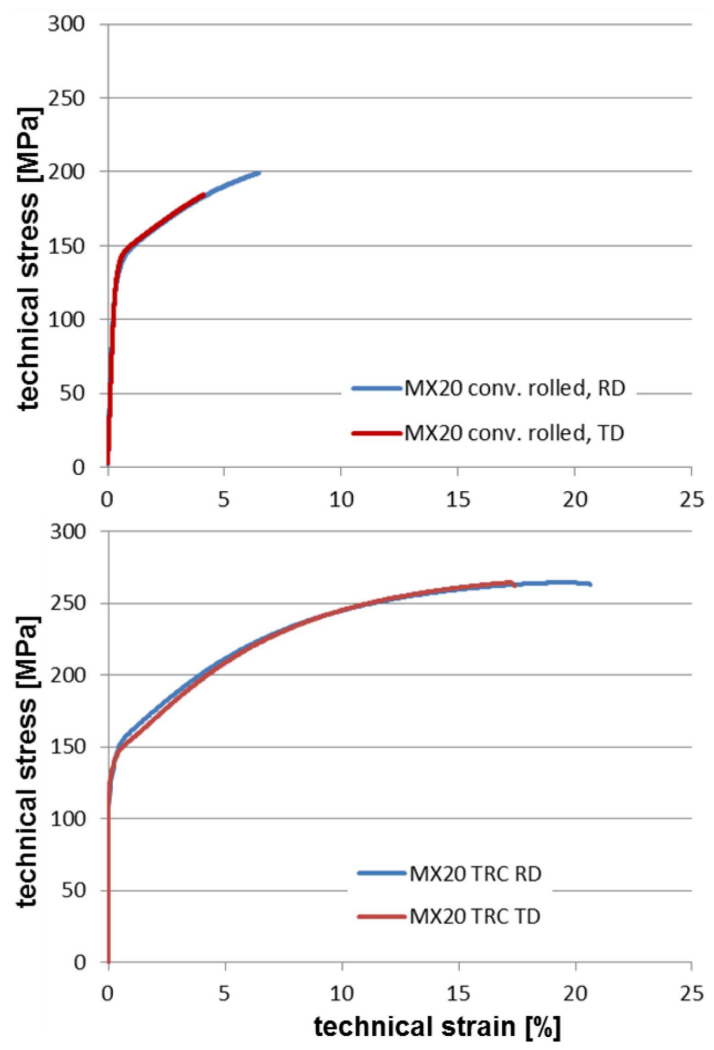

Fig. 7. Stress strain diagrams of both MX20 sheets. 


\section{Mechanical properties}

In order to see how the different processing routes influence the ductility of the sheets, tensile tests were performed. The comparative stress-strain diagrams of both sheets are shown in Fig. 6. In general, it can be observed for both sheets that the tensile yield stress (TYS) and the ultimate tensile stress (UTS) in transverse direction (TD) are slightly higher than in rolling direction (RD), but the elongation at fracture in TD is lower than in RD. The reason for the higher TYS and UTS lies in the resulting textures, where the basal planes are slightly tilted in $\mathrm{RD}$. The sheets produced via twin roll casting exhibit higher ductility especially in $\mathrm{RD}$, compared to the conventional produced sheets, which corresponds to the formation of stringers in the microstructure of the conventional rolled sheets. This is also the reason why the UTS in the twin roll cast sheet is significantly higher than in the conventionally produced sheets. The TYS is for all sheets on the same level.

\section{Conclusion}

The results reveal that the production process has a significant influence on the properties of the resulting sheets. It is shown that the sheet produced via twin roll casting achieves a higher ductility and UTS compared to the conventional produced ones. On the one hand, this could be seen as a result of the formation of finer precipitates in the twin roll cast strip compared to the conventional rolled material caused by the much higher solidification rate in this process. The finer precipitates in the strip material are in the final sheet more located at the grain boundaries. The coarse precipitates in the cast billets form stringers in the microstructure of sheets during rolling, which reduces the ductility and strength significantly. On the other hand, the minor thickness of the strip material results in a minor total degree of deformation in the sheets, which reduces the risk defects in the final sheets. Furthermore, in comparison to the conventional rolled sheets those produced by twin roll casting show the same shape of texture but with a less pronounced intensity because of the minor number of rolling passes needed to reach final gauge. The subsequent texture measurements also make clear that a heat treatment after rolling decreases the texture intensities substantially in both cases.

\section{Acknowledgments}

This research was performed as a joint research project in the research program "r3-Innovative Technologien für Ressourceneffizienz-Strategische Metalle und Mineralien" within the framework "Forschung für nachhaltige Entwicklung". The project "Substitution of rare earth elements in high strength and ductile Magnesium sheet material - SubSEEMag" was financially supported by the German Federal Ministry of Education and Research. We also want to thank the colleagues from the Institute of Metal Forming at the TU Bergakademie Freiberg for supplying the twin roll cast strip.

\section{References}

[1] L. Stutz, J. Bohlen, G. Kurz, D. Letzig, K.U. Kainer, Key Eng. Mater. 473, 335 (2011).

[2] C.E. Dreyer, W.V. Chiu, R.H. Wagoner, S.R. Agnew, J. Mater. Process. Technol. 210, 37 (2010).

[3] L. Stutz, J. Bohlen, D. Letzig, K.U. Kainer, in: Magnesium Technology 2011, The Minerals, Metals, and Materials Society TMS, Warrendale (PA) 2011, p. 373.

[4] K. Hantzsche, J. Wendt, K.U. Kainer, J. Bohlen, D. Letzig, JOM 61, 43 (2009).

[5] J. Bohlen, M. Nürnberg, J.W. Senn, D. Letzig, S.R. Agnew, Acta Mater. 55, 2101 (2007).

[6] S.B. Yi, D. Letzig, R. Gonzalez-Martinez, K. Hantzsche, J. Bohlen, I. Schestakow, S. Zaefferer, in: Thermec 2009, Berlin 2009, p. 1506.

[7] J. Bohlen, J. Wendt, M. Nienaber, K.U. Kainer, L. Stutz, D. Letzig, Mater. Character. 101, 144 (2015).

[8] S. Yi, J.H. Park, D. Letzig, O.D. Kwon, K.U. Kainer, J.J. Kim, in: TMS Magnesium Technology 2016, p. 383.

[9] V. Kree, J. Bohlen, D. Letzig, K.U. Kainer, Prakt. Metallogr. 5, 233 (2004).

[10] F. Bachmann, R. Hielscher, H. Schaeben, Solid State Phenom. 160, 63 (2010). 